\title{
A MODERNIDADE EM CONSTRUÇÃO POLÍTICAS PÚBLICAS PARA MÚSICA E PRODUÇÃO MUSICAL EM CURITIBA - 1971 a 1983
}

\author{
Ulisses Quadros de Moraes \\ Mestrando em História, linha de pesquisa Cultura e Poder, na Universidade \\ Federal do Paraná.
}

\section{Introdução}

No presente artigo, discuto uma questão que me parece central para a compreensão do alcance das ações artísticas curitibanas no período de 1971 a 1983. Trata-se da modernização dos equipamentos públicos de arte e cultura $^{1}$ na cidade de Curitiba, levada a cabo a partir da primeira administração do prefeito Jaime Lerner. Essa modernização criaria as condições necessárias para a implementação de políticas públicas mais efetivas para todos os segmentos artísticos, com vistas à promoção de uma verdadeira mudança cultural na cidade ${ }^{2}$. Assim, as artes plásticas, a música, o teatro e o cinema foram contemplados com ações diretas para a construção de espaços públicos importantes na cidade de Curitiba. No presente trabalho, no entanto, vou me ater apenas às ações voltadas para a música popular, foco de minhas pesquisas de mestrado.

Para construir as bases do meu ponto de vista, recorri ao exposto no livro "A Moderna Tradição Brasileira", onde o autor, ao discorrer sobre o movimento modernista brasileiro, defende a idéia de que

\footnotetext{
${ }^{1}$ Em um pequeno texto de abertura para o seminário "Cidade é Arte, Cidade é Cultura", organizado pelo Setorial de Cultura do Partido dos Trabalhadores sob minha coordenação em 19 de junho de 2004, no SESC da Esquina em Curitiba, discorro sobre as diferenças dos conceitos de Arte e Cultura, comumente negligenciadas. Nesse Seminário estiveram presentes Marcelo Sandmann, professor de literatura portuguesa da UFPR, Vitor Ortiz, então secretário da Cultura de Porto Alegre, Bernardo Pellegrini, então Secretário da Cultura de Londrina, Cláudio Manberti, Secretário das diversidades culturais do Ministério da Cultura, Ângelo Vanhoni, deputado estadual no Paraná, Cláudio Fajardo, presidente da Biblioteca Pública do Paraná e Antonio Grassi, então presidente da FUNARTE.

2 Como já mencionei em outro artigo (MORAES, 2006), no sitio da Fundação Cultural de Curitiba www.fundacaoculturaldecuritiba.com.br, a respeito do Teatro do Paiol consta: "Antigo Paiol de Pólvora transformado em teatro em 1971, o Teatro do Paiol é um símbolo cultural e histórico de Curitiba. Sua criação foi o marco das reformas urbanísticas e culturais implementadas na cidade a partir da década de 70. (...)" (grifo meu).
} 
“(...) a noção de modernidade está "fora do lugar" na medida em que o Modernismo ocorre no Brasil sem modernização. Não é por acaso que os críticos literários têm afirmado que o Modernismo da década de 20 "antecipa" mudanças que irão se concretizar somente nos anos posteriores." (ORTIZ, 2006, p. 32)

Para Renato Ortiz, seria apenas ao longo das décadas de 50, 60 (principalmente) e 70, que o Brasil contaria com as bases necessárias para a existência de uma indústria cultural. Esse argumento norteia-se por alguns elementos bastante importantes de análise estrutural brasileira em relação, principalmente, às condições necessárias para a instauração de um parque industrial voltado para a produção, divulgação e distribuição dos bens artísticos produzidos em larga escala.

$\mathrm{O}$ autor recorre a preceitos defendidos por Perry Anderson para descrever o contexto em que se dá a modernização européia na primeira metade do século XX. Anderson descreve o que, a seu ver, seriam as três condições necessárias para o surgimento do modernismo naquele continente:

"A primeira diz respeito a um passado clássico, altamente formalizado nas artes visuais e institucionalizado pelo Estado. Este passado cumpriria uma dupla função: ele é fonte de tradição artística e referência obrigatória para os críticos do academicismo oficial. A segunda coordenada está vinculada às inovações tecnológicas que conhece a sociedade européia neste período - telefonia, fotografia, telégrafo, automóvel, avião -, mas que encontram ainda restritas a um pequeno grupo da sociedade. Ao terceiro elemento, Perry Anderson denomina "proximidade imaginativa da revolução social", ou seja, existiria "no ar" uma esperança de transformação política que habitava diferentes setores sociais. Por isso o autor pode afirmar que "o modernismo europeu nos primeiros anos deste século floresceu no espaço situado entre um passado clássico ainda utilizável, um presente técnico ainda indeterminado e um futuro político ainda imprevisível”. (ORTIZ, 2006, p. 104 e105).

A realidade brasileira, no entanto, se mostrava sensivelmente diferente se comparada à européia. Um passado clássico, por exemplo, o Brasil não possuía. Mas no que se refere aos dois outros "pilares" havia as condições favoráveis à chegada da modernidade. Em outras palavras, a implementação, nas décadas de 50 e 60, de um parque tecnológico condizente com as necessidades da grande indústria de entretenimento e a proximidade imaginativa da revolução social, existiam no Brasil.

Em relação às inovações tecnológicas, com o advento do golpe militar de 64, uma das questões fundamentais para a "segurança nacional" viria a ser a criação de uma malha de comunicação eficiente e que abrangesse todo o território nacional. Isso foi satisfatoriamente conquistado com vultosos investimentos públicos em todo o Brasil bem como através de ações da Empresa Brasileira de Telecomunicações - EMBRATEL que, 
em 1968, já abrangia quase a totalidade do território nacional no que diz respeito à capacidade técnica de transferência de dados. A indústria televisiva e radiofônica que seriam enormemente beneficiadas com essa realidade se tornaria, por outro lado, refém do regime, cumprindo um papel de integração nacional ao mesmo tempo em que se isentava de pesadas críticas ao Estado ditatorial. Um jogo com regras bastante claras no campo político.

No que se refere aos anseios de mudanças sociais, o Brasil vivia certa efervescência pré-revolucionária desde o pós-guerra. Após o sucesso da revolução cubana em 1959, a primeira investida do gênero na América Latina, movimentos populares ganham força e presença nas grandes questões nacionais, principalmente no governo do presidente João Goulart. Com sua deposição em 64, diversas ações culturais foram responsáveis pela constituição da "resistência". Os CPC da UNE, movimentos teatrais e cinematográficos, além de produções de grandes nomes da música popular - para citar apenas alguns relacionados às artes e às culturas - vivem momentos de incorporação das questões nacionais e a valorização de elementos de brasilidade, em oposição ao "imperialismo cultural norteamericano". Com isso as bases para o nascimento tardio da modernidade brasileira estavam lançadas.

Já em Curitiba, uma capital distante dos grandes centros nacionais, a realidade seria um pouco diferente. Até a década de 60, por exemplo, a cidade contava apenas com o teatro Guaíra e o teatro da Reitoria, como já dito. Além disso, pela ausência de grandes empresas de comunicação, concentradas em São Paulo e no Rio de Janeiro, as iniciativas culturais dependiam de recursos estatais em suas mais diversas instâncias. O poder público funcionava como um órgão compensatório às produções artísticas distantes da indústria cultural e do consumo de massa. Assim, uma ação mais efetiva do poder público municipal a partir da década de 70 , viria a ser um dos acontecimentos mais importantes para as artes curitibanas. Isso, pelo exposto anteriormente, com um pequeno atraso em relação ao ocorrido no eixo Rio - São Paulo, que já contava com redes de rádio e televisão em expansão para todo o país, fomentando um mercado consumidor para seus "produtos culturais"3.

\footnotetext{
${ }^{3}$ Para se ter uma idéia, a primeira rádio com Freqüências Moduladas (FM) em Curitiba data de 10 de março de 1977. Trata-se da Rádio Transamérica, então pertencente ao grupo do Banco Real. Sua programação era montada nos estúdios do Rio de Janeiro e a retransmissão feita, em Curitiba, a partir
} 
Isto posto, defendo a idéia que houve um atraso dentro do atraso, ou seja, Curitiba iria "acertar seus ponteiros" com as cidades centrais, entenda-se Rio de Janeiro e São Paulo, apenas ao longo da década de 70, posteriormente a consolidação de uma "indústria cultural" no Brasil. Esse pequeno atraso pode ter significado a dificuldade de inserção da produção local no contexto nacional. Em linguagem popular, talvez Curitiba tenha "perdido o bonde da história". Mas isso extrapola os objetivos aqui expostos, ficando sua análise para futuras ponderações.

\section{Ações públicas rumo ao futuro}

É certo que a implantação do que se costumou chamar de "Indústria Cultural ${ }^{\text {" }}$ ocorreu com ações mistas do capital privado (grandes editoras, gravadoras, distribuidoras e empresas de comunicação, onde podemos destacar o início da rede televisiva brasileira) e o Estado, que ocupou um lugar central e exclusivo na implementação da malha nacional de transferência de informação. Em meio ao regime de exceção inaugurado em abril de 64, o Estado brasileiro iria investir vultosos recursos no aprimoramento tecnológico das comunicações. Grandes empresas como redes televisivas, radiofônicas e da imprensa escrita, encontraram um ambiente amplamente favorável ao seu crescimento. Essa parceria estaria fadada ao sucesso em âmbito nacional, com a manutenção de uma característica: a concentração dessa indústria nas cidades de São Paulo e Rio de Janeiro.

Em regiões periféricas, o papel dos investimentos públicos ganha importância. Na ausência de um ambiente consumidor regional capaz de amparar as produções, tais recursos funcionariam para alicerçar uma gama de realizações por demais distantes das empresas de produção, promoção e

da rua Desembargador Hugo Simas, no bairro do Pilarzinho. (publicado no jornal O Estado do Paraná, suplemento Tablóide, por Aramis Millarch, em 08/01/2977).

${ }^{4}$ A esse respeito, podemos nos utilizar de um breve esclarecimento: "No caso das modernas sociedades industrializadas é comum que elas sejam consideradas como sociedades de massa, onde as instituições dominantes têm de prover e até mesmo criar as necessidades de multidões e de seus participantes anônimos, da mesma forma que desenvolvem mecanismos eficazes para controlar essas massas humanas, fazê-las produzir, consumir e se conformar com seus destinos e sonhos. (...) Tais instrumentos serial principalmente o rádio, a televisão, a imprensa e o cinema. Essa cultura homogeneizadora, niveladora, teria o núcleo de sua existência num setor específico de atividade, a indústria cultural. (...) Não há dúvida de que a indústria da cultura, centrada nesses meios de comunicação de massa, é um elemento muito importante dessas sociedades modernas". (SANTOS, p. 46). 
distribuição em nível nacional. Um papel que, em Curitiba, começa a se esboçar efetivamente apenas no início dos anos 70.

É nesse ambiente que toma posse, em 1971, um jovem arquiteto que teve participação ativa na elaboração de um novo plano diretor para Curitiba em meados dos anos 60, e que seria implementado a partir dos anos 70. Seu nome era Jaime Lerner, e trazia consigo visões urbanísticas e administrativas inovadoras. Com excelentes relações, Lerner é nomeado para o cargo de prefeito de Curitiba pelo governador do Paraná, Haroldo Leon Perez, para um mandato de quatro anos e, já nos primeiros momentos mostra a que veio. Num projeto ambicioso, implementa profundas modificações na cidade, fixando uma imagem de eficiência e retidão, que lhe renderiam frutos políticos positivos até o final da década de 90.

\section{O paiol de pólvora}

No campo artístico, num gesto simbólico de um prefeito que entraria para a história como um precursor de práticas urbanísticas contemporâneas. Já em 1971, com menos de um ano de mandato, Jaime Lerner inicia um projeto de "modernização" da cidade de Curitiba, onde se destaca, dentre outros, a inauguração do Teatro do Paiol ${ }^{5}$, antigo depósito de pólvora, uma reivindicação da classe artística local. Com um show de Toquinho, Vinícius de Morais, Marilia Medalha e o Trio Mocotó, nos dias 27, 28, 29 e 30 de dezembro $^{6}$, em pleno recesso das festas de fim de ano, Curitiba ganha um espaço inédito. Uma iniciativa considerável já que a capital do estado, em termos de equipamentos públicos, contava apenas com o teatro da Reitoria

5 Para ilustrar a importância desse ato para o ideário dos seguidores de Jaimer Lerner, Aramir Millarch escreve: "O Paiol ficou como símbolo da Fundação Cultural - que seria criada alguns meses depois graças, especialmente, ao empenho do então conselheiro Eduardo Rocha Virmond. Mesmo com toda a babaquice, intolerância, rancor e incompetência de algumas administrações que se seguiram, ficou não só o Paiol como logotipo, mas como símbolo do mais iluminado instante cultural da primeira administração de Jaime Lerner - e que transformaria em muitos aspectos a cidade" (grifo meu). (IPPUC, vol. 4, p. 85)

6 Em homenagem ao Teatro Paiol, Vinicius de Morais compôs uma canção apresentada no dia 30 de dezembro, em Curitiba. Proibida sua gravação e apresentação pública pelo regime militar, por considera-la ofensiva (o Paiol de pólvora seria uma metáfora representando o Brasil), o único registro fonográfico dessa música consta no LP com a trilha sonora da novela $\mathrm{O}$ Bem Amado, de Dias Gomes. 
- UFPR e com o Teatro Guaíra, ainda a meio vapor7, vinculado a Secretaria de Estado da Cultura.

A inauguração do Paiol pode ser considerada um marco na história recente curitibana. Em seu palco foram realizadas apresentações de artistas de renome nacional, antes restritas a poucos espaços sob responsabilidade de outras esferas do poder. A começar pelo grandioso espetáculo de estréia, o Paiol ainda recebeu

“(...) importantes figuras da MPB: Elis Regina, Ivan Lins, João Bosco, Dick Farney, Dona Ivone Lara, Alaíde Costa, Nora Ney, Carmélia Alves, Elza Soares, Carmem Costa, Célia, Leni Andrade, Gonzaguinha, Moreira da Silva, Cida Moreira. E nossos grands nomes, Marinho Galera, Paulo Vítula, Rosi Greca, Tatara e Lápis, (...).” (SANSONE, 2000, p. 17).

Tais espetáculos ocorreram ao longo de toda a história do Teatro, a despeito das oscilações de investimento que tenham ocorrido em administrações posteriores. Ainda assim, podemos perceber indícios claros de uma mudança significativa no panorama cultural de Curitiba, que então passa a contar com ações efetivas da prefeitura em promoções de eventos artísticos de grande monta.

\section{A fundação cultural e suas ações}

Um pouco mais adiante, em 5 de janeiro de 1973, é criada a Fundação Cultural de Curitiba através da Lei Ordinária $4545^{\circ}$, que passaria a elaborar, implantar e administrar as ações públicas dirigidas à Cultura.

Podemos considerar esse acontecimento também como um marco para a capital paranaense, já que sinaliza uma estratégia de construção de um aparato físico capaz de dar suporte efetivo às novas políticas públicas. O órgão, com status de Secretaria, estaria ligado diretamente ao poder executivo, como especifica o artigo $3^{\circ}$.

\footnotetext{
7 A inauguração definitiva do teatro Guaíra ocorreu apenas em 1974, com o término das reformas que se mantiveram por 24 anos.

8 A Lei, assinada por Jaime Lerner, cria a Fundação Cultural de Curitiba e especifica suas atividades nos $\operatorname{artigos} 1^{\circ}$ e $2^{\circ}$.

9 “A Fundação será administrada por dois órgãos: a sua Diretoria Executiva, composta de três membros de livre escolha do chefe do poder executivo; e o Conselho Deliberativo, presidido pelo Prefeito Municipal (grifo meu), tendo como Vice-presidente o Diretor Executivo da Fundação, e composto de mais cinco membros, além dos membros da Diretoria Executiva, nomeados pelo Chefe do Poder Executivo, entre pessoas que tenham nível artístico e cultural elevado (grifo meu), todos com mandato de três anos".
} 
De uma posição meramente coadjuvante até fins dos anos 60 , a prefeitura de Curitiba começa sua trajetória no sentido de se tornar protagonista nas realizações artísticas e culturais na capital do Estado. Institui uma política de criação de equipamentos públicos capazes de realizar as tão sonhadas "reformas (...) culturais implementadas na cidade a partir da década de 70". O mapa artístico da cidade começa a ser redefinido com ações voltadas para as mais diversas áreas.

Exemplos não faltam. Em 1974, é criada a Camerata Angicua de Curitiba, numa importante iniciativa do maestro Roberto de Regina e da cravista Ingrid Seraphin. Voltada para a divulgação da música erudita, a Camerata nasceria sob a responsabilidade direta da Fundação Cultural, recebendo recursos para a realização de um amplo calendário de apresentações e registros sonoros em Curitiba, em importantes cidades brasileiras e no exterior.

No campo da música popular, numa parceria entre a Fundação Cultural de Curitiba e um grupo de músicos, compositores e produtores, acontece o MAPA - Movimento Atuação Paiol. Como resultado, um LP10 foi gravado e fabricado unicamente com investimentos públicos oriundos da Fundação Cultural e de uma parceria com o então Ministério da Educação - MEC. O primeiro mandato do jovem arquiteto Jaime Lerner, 1971 a 1974, termina com um sensível incremento nos equipamentos artísticos públicos da cidade, num movimento rumo a "modernidade".

Posteriormente, tem início o mandato de Saul Raiz (1975 a 1978), amigo e admirador de Lerner, porém não tão simpático às causas culturais. Da-se um pequeno hiato entre os anos 75 e 78 , onde os poucos recursos financeiras destinados à Fundação Cultural limitariam sua ação e comprometeriam a manutenção da administração anterior. Ainda assim, podemos destacar a criação, na galeria Júlio Moreira, centro da cidade, do Teatro Universitário de Curitiba, o TUC (1976); o Teatro do Piá (1978), localizado na antiga sede da Fundação Cultural de Curitiba, no Largo da Ordem, também centro da cidade, destinado exclusivamente ao público

\footnotetext{
${ }^{10}$ O LP conta com as seguintes canções e compositores: lado A - Porto Seguro (Carlos Bueno); Festafeira (Celso Loch e Paulo Leminski); Modinha (Sergio Maluf); Sem Maneiras (Phebus Moschos); Imagens Latinas (Celso Loch). Lado B - Receita (Marinho Galera e Paulo Vítola); Coisa Triste (Gerson Físben); Ela (Jose Roberto Bastos Oliva); Sei lá (Luis Fernando Amaral Avi) e Que há de novo? (Marinho Galera). Lançado em 1976, o disco foi gravado em quatro canais no SIR laboratórios - Imagem e Som, com direção musical de Roberto Nascimento e coordenação geral de Marinho Galera.
} 
infantil; o Circo Chic-Chic, criado em 1976 e rebatizado em 1979 de Circo da Cidade, importante ação voltada para apresentações e oficinas de cultura popular em regiões periféricas de Curitiba; dentre outras.

Com a volta de Jaime Lerner à prefeitura de Curitiba para mais um mandato - 1979 a 1983 -, os incentivos às ações artísticas são retomadas, ainda que com um fôlego menor se comparadas às de sua primeira administração. Em plena crise que assolou o Brasil a partir de 1973, os investimentos nas áreas consideradas como não essenciais perdem espaço. As ações públicas nas áreas artísticas sofrem um grande revés, ainda que alguns espaços importantes como o Centro Cultural Solar do Barão ${ }^{11}$, inaugurado no início de 1983 após dois anos de trabalhos de restaurações, tenham sido inaugurados.

O objetivo parecia cumprido: a prefeitura contava com grande número de espaços físicos relativamente bem equipados, ações em todas as áreas artísticas e um caminho definido para essas ações ao longo de 12 anos ininterruptos de poder.

Efetiva-se, assim, a ação do poder municipal em relação a políticas públicas para as artes e as culturas no período que corresponde aos anos 1971 a 1983 que, aliadas à outras ações de grande impacto ${ }^{12}$, solidificariam uma verdadeira hegemonia política de um grupo cuja estrela maior foi, sem dúvida, o senhor Jaime Lerner, e que, em âmbito municipal, mantêm-se até os dias de hoje.

\section{Conclusão}

O impacto das administrações de Jaimer Lerner e Saul Raiz ao longo dos anos 70 e início dos 80, ainda está por ser pormenorizado, pelo menos no que diz respeito às ações voltadas para as Artes e às Culturas.

É certo que as inúmeras iniciativas, principalmente aquelas voltadas para a criação de espaços físicos, foram determinantes para um avanço nas ações públicas para todas as manifestações artísticas. Seus resultados

\footnotetext{
11 O Centro Cultural Solar do Barão, prédio histórico construído em 1880, após dois anos de trabalhos de restaurações, foi "inaugurado pelo prefeito Jaime Lerner como espaço cultural em 1983, \{sendo então\} sede do Museu da Gravura Cidade de Curitiba, do Museu da Fotografia Cidade de Curitiba, do Museu do Cartaz, da Gibiteca de Curitiba, do Centro de Documentação e Pesquisa-Farol do Saber Guido Viaro e da Coordenação de Música da FCC”. (SANSONE, 2000, p.68).

12 Inúmeras realizações desse período, bem como uma análise crítica de seus processos e resultados, podem ser conferidas no livro "Curitiba e o mito da cidade modelo". (DENNISON, 2000).
} 
práticos devem ser avaliados à guisa das fontes disponíveis em abundância na Casa da Memória - Fundação Cultural de Curitiba, na Fundação Teatro Guaíra, em arquivos da Câmara Municipal de Curitiba, de periódicos locais, etc. Entretanto, o que já nos é permitido concluir diz respeito à eficiência administrativa desse grupo, pelo menos em relação ao foco de nossa pesquisa.

$\mathrm{Na}$ construção de sua hegemonia dentro do campo político e em suas relações com os campos artístico e jornalístico locais, o Lernismo deixou marcas profundas na cidade de Curitiba. A criação da Fundação Cultural de Curitiba, de vários teatros por toda a cidade, de inúmeros centros culturais importantes, além de ações efetivas em parceria com movimentos artísticos locais, foram decisivas para os movimentos artísticos não só na década de 70 , mas nos anos posteriores.

A partir de 1983, seguiram-se duas administrações do Partido do Movimento Democrático Brasileiro - PMDB, a de Roberto Requião e a de Maurício Fruet. Ambas também tentaram registrar "suas marcas" na cidade em aberta oposição aos governos anteriores. Entretanto, quase todo o parque físico cultural já estava completado, pelo menos nas regiões centrais da cidade, por onde transitam grande parte dos chamados formadores de opinião. $O$ que restou aos representantes do PMDB foram ações localizadas, ainda que bastante modestas se comparadas às do período anterior.

Ainda será necessária uma análise mais cuidadosa para que se possam entender melhor os efeitos desse que foi, sem dúvida, um dos mais bem sucedidos empreendimentos administrativos da história recente de Curitiba.

\section{Bibliografia}

BOURDIEU, Pierre. A economia das trocas simbólicas. São Paulo: Ed. Perspectiva, 2005. . As regras da arte. São Paulo: Ed. Schwarcz, 2002. . O poder simbólico. Rio de Janeiro: Bertrand Brasil, 2003. . Rãões Práticas: sobre a teoria da ação. Campinas (SP): Papirus Editora, 2005.

CHARTIER, Roger. Pierre Bourdien e a bistória - debate com José Sérgio Leite Lopes. Palestra proferida na UFRJ, Rio de Janeiro, 30 abril 2002.

FAVARETTO, Celso. Tropicália Alegoria Alegria. Cotia (SP): Ateliê Editorial, 2000.

FIGUEIREDO, Anna Cristina C. Moraes. Liberdade é uma calça velha, azul e desbotada: publicidade, cultura de consumo e comportamento político no Brasil - 1954-1964. São Paulo: HUCITEC, 1998.

KELLER, Douglas. A cultura da mídia. Bauru: EDUSC, 2001. 
MELLO, Zuza Homem de. A era dos festivais - uma parábola. São Paulo: Editora 34, 2003.

MOTTA, Nelson. Noites tropicais - solos, improvisos e memórias musicais. Rio de Janeiro: Editora Objetiva, 2000.

NAPOLITANO, Marcos. Cultura e poder no Brasil contemporâneo. Curitiba: Juruá Editora, 2005. .. História e música. Belo Horizonte: Ed. Autêntica, 2002.

O Conceito de "MPB" nos anos 60. In: MPB. História: Questões e Debates, n 31. Curitiba: Editora UFPR, 2000. p. 11-30.

. Seguindo a canção - engajamento político e indústria cultural na MPB (1959 - 1969). São Paulo: ANNABLUME, 2001.

OLIVEIRA, Dennison. Curitiba e o mito da cidade modelo. Curitiba: Editora UFPR, 2000.

ORTIZ, Renato. A Moderna Tradição Brasileira. São Paulo: Ed. Brasiliense, 2001.

ORTIZ, Renato (org.). A Sociologia de Pierre Bourdieu. São Paulo: Editora Olho

D’água , 2005.

SANDMANN, M. Algumas canções em Curitiba. In: Revista Letras, no 45, Curitiba, Editora da UFPR, 1996.

. Lá vai fandango com tamanco meu sinhô. In: ENCONTRO NACIONAL DA ASSOCIAÇÃO BRASILEIRA DE ETNOMUSICOLOGIA - ABET, 1, 2002, Recife.

TATIT, Luiz. O cancionista - composição de canções no Brasil. São Paulo: EDUSP, 2002.

VAZ, Toninho. Paulo Leminski - o bandido que sabia latim. São Paulo: Record, 2005.

VELOSO, Caetano. Verdade tropical. São Paulo: Companhia das letras, 2004.

WARNIER, Jean-Pierre. A mundialização da cultura. Bauru: EDUSC, 2000.

WISNIK, José Miguel. O som e o sentido - uma outra história das músicas. São Paulo: Companhia das Letras, 2004.

\section{Fontes pesquisadas SITES}

CÂMARA MUNICIPAL DE CURITIBA. Leis Ordinárias do Município. Arquivo digital disponível no endereço eletrônico http://www.cmc.pr.gov.br

FUNDAÇÃO CULTURAL DE CURITIBA, sítio oficial disponível no endereço eletrônico http://www.fundacaoculturaldecuritiba.com.br

MILLARCH, Aramis. Artigos publicados no Jornal O Estado do Paraná, no período de 1971 a 1983, digitalizados e disponíveis no sitio oficial no endereço http://www.millarch.org/principa.asp

LP

MAPA. Fundação Cultural de Curitiba, 1976.

Curitiba, a cidade da gente. Fundação Cultural de Curitiba, 1982.

\section{Publicações oficiais}

FUNDAÇ̃̃ CULTURAL DE CURITIBA. Aramis Millarch. Boletim informativo da casa Romário Martins. Curitiba: Fundação Cultural, 1992.

INSTITUTO DE PESPQUISA E PLANEJAMENTO URBANO DE CURITIBA - IPUC. Memória da Curitiba Urbana. Obra em sete volumes publicada no início dos anos 90, traz depoimentos de administradores e funcionários da prefeitura de Curitiba.

SANSONE, Margarita Pericás. Fundação Cultural de Curitiba no limiar do novo milênio. Curitiba: Fundação Cultural, 2000. 